\title{
Editors' Introduction to the Special Issue on "MATCOS conference"
}

Dear Reader,

about ten years ago in the frame of collaboration between the universities in Szeged and in Ljubljana we decided to organize a conference which set an aim to bring the theory and the practice closer to each other. The first conference"First Mini Conference on Theoretical Computer Science" - was organized in 2008. Feedback was showing that the conference was well accepted and we decided to organize the new conference regularly. In the meantime, the conference's popularity grew and researchers from more and more countries took part in it. Therefore, we decided to "rename" the conference to MATCOS (Middle-European Conference on Applied Theoretical COmputer Science). Besides the harmony of the theory and the practice we also wanted to highlight the cooperation and dialogue between senior and junior researchers. Consequently, we organized separate sessions for PhD students. It became customary, that the first day student papers and the invited talk were presented, and they were followed by the presentation of regular papers. At the same time the conference also moved to the Coast, to the city of Koper and the University of Primorska.

Among these conferences the last one was organized in 2016, and from the presented papers the programme committee decided to invite nine papers for a special issue of Informatica. All papers were rigorously reviewed. The papers reflect the general spirit of the MATCOS as they sweep from the theoretical aspects to the study of practical problems.
The programme committee of MATCOS 2016 was:

\author{
Jacek Blazevicz (Poznan, Poland) \\ Andrej Brodnik (Koper, Ljubljana, Slovenia) co-chair \\ Angel Corberan (Valencia, Spain) \\ Ruben Dorado Vicente (Jaén, Spain) \\ Elena Fernandez (Barcelona, Spain) \\ Gábor Galambos (Szeged, Hungary) co-chair \\ Gabriel Istrate (Timisoara, Romania) \\ Miklós Krész (Szeged, Hungary) \\ Silvano Martello (Bologna, Italy) \\ Benedek Nagy (Famagusta, Cyprus, Turkey) \\ Gerhard Reinelt (Heidelberg, Germany) \\ Giovanni Rinaldi (Rome, Italy) \\ Borut Žalik (Maribor, Slovenia)
}

Koper, Ljubljana, Szeged, October 2018 
